\title{
Examining the Development of Positive Space in Health and Social Service Organizations: A Canadian Exploratory Study
}

\author{
JUDITH A. MACDONNELL and ANDREA DALEY \\ York University, Toronto, Ontario, Canada
}

All health care sectors are currently examining factors that influence delivery of high-quality services for diverse groups with an understanding that minority populations experience barriers to service access that contribute to well-documented ill bealth and health inequities. With a goal of understanding dynamics that can improve access to care in the home care sector, this qualitative exploratory study examined processes to create inclusive, positive space for diverse lesbians, gay men, bisexuals, transgender, and queer (LGBTQ) people in community-based bealth and social service agencies. A purposeful sample of eight key informants from agencies in Toronto, Ontario, Canada, which offer programs and services to LGBTQ communities, completed in-depth interviews. Conventional content analysis and a critical lens were used. Themes offered insight into the histories, challenges, and turning points which shaped the development of LGBTQ-positive spaces in these organizations. Community engagement and leadership emerged as relevant, as did strategies to embed LGBTQ voices and visibility within everyday organizational functioning. Given the gap in literature addressing LGBTQ access to home care and the unique dynamics that shape care in the home, implications address the application of these study findings for creating positive space in the bome care sector.

KEYWORDS affirmative practice, affirmative policy, gay, lesbian, bisexual, transgender, organizational change

Address correspondence to Judith A. MacDonnell, School of Nursing, York University, HNES Building, Room 322, 4700 Keele Street, Toronto, Ontario M3J 1P3, Canada. E-mail: jmacdonn@yorku.ca 
Health care and social service sectors are currently examining factors that influence the delivery of high-quality health and social services for diverse groups, and this often includes a focus on developing the cultural competence of individual providers and larger organizational change (Whealin \& Ruzek, 2008; Wilkerson, Rybicki, Barber, \& Smolenski, 2011). Certainly, a solid literature in Canada and beyond indicates health inequities for diverse groups of lesbian, gay, bisexual, transgender, and queer (LGBTQ) people across age, culture, ethnicity, for example, including challenges to accessing relevant programs and services for health concerns such as preventive care, chronic disease, and mental health (e.g., Bauer, Travers, Hammond, \& Boyce, 2007; Dean et al., 2000; Fish, 2009; Mulé et al., 2009; Registered Nurses Association of Ontario [RNAO], 2007). Complex gendered dynamics influence how diverse patients/clients experience and understand health care and social service provision (Armstrong et al., 2003). For LGBTQ people, gender, sexuality, and its intersections with race, class, and other social dynamics shape relationships of care and working conditions given the heteronormativity that informs invisibility, providers' discomfort and lack of knowledge, and barriers to disclosure for workers and patients/clients (Fish, 2009; Gapka et al., 2004; Mulé et al., 2009; Röndahl, Innala, \& Carlsson, 2007).

Such approaches often call for systemic action in organizations and professions that moves beyond the important, but limited, development of individual practitioners' skill sets that focus on understanding attributes of different cultures. Instead, this considers the complex and deeply embedded dynamics of power and privilege that are embedded in all social organizations (e.g., Daley \& MacDonnell, 2011; McGibbon \& Etowa, 2009; Wilkerson et al., 2011). Explicit attention to organizational and curriculum goals aligned with human rights demands a focus on the processes whereby change occurs, along with dimensions of responsive and supportive environments for diverse groups (Dobinson, MacDonnell, Hampson, Clipsham, \& Chow, 2005; Gapka et al., 2004; Gay, Lesbian, Bisexual and Transgender Health Access Project, 2010; MacDonnell \& Andrews, 2006; Moore, 2009). However, there is little research that reflects organizational accounts of moving toward these goals, hence this research to examine the development of positive space.

In this article we examine the development of inclusive environments in health and social service organizations known for their LGBTQ-positive care as described by key informants (KIs) in an urban Canadian context. The term positive space has been used to describe programs and initiatives that aim to create welcoming environments for lesbians, gay men, bisexuals, transgender, and queer (GLBTQ) people in a range of settings, given the barriers to access many encounter from the deeply embedded heterosexism/homophobia, biphobia, and transphobia that have historically pervaded 
and continue to shape many health and social services (Gay and Lesbian Medical Association [GLMA], 2001; Johnson, Mimiaga, \& Bradford, 2008; Mulé et al., 2009; Ontario Public Health Association [OPHA], 2011; University of Toronto, 2014; Valentine, Wood, \& Plummer, 2009). In fact, invisibility and marginalization of the holistic concerns of LGBTQ people often prevail in health and social care (Eliason, Dibble, \& DeJoseph, 2010; McNair \& Hagarty, 2010). Heterosexism is the assumption that opposite-sex, male/female relationships are the norm and preferred; as such same-sex sexual orientation, relevant to the lives of lesbians, gay men, and bisexuals, is overlooked, discounted, pathologized, or invisible. For transgender people, gender identity (one's sense of being male, female, both, or neither) can be a defining aspect of oneself, yet it too is often invisible.

The term affirmative practice, rather than positive space, has been used in social work, counseling, and some educational literature to refer to practitioner practices that create positive and inclusive spaces for LGBTQ people (Biaggio, Orchard, Larson, Petrino, \& Mihara, 2003; Bridges, Selvidge, \& Matthews, 2003; Crisp, 2007; Mottet \& Tanis, 2008), although attention to the organizational environment varies in this context. ${ }^{1}$ For instance, Crisp (2007), noting that affirmative practice is a fairly recent concept, built on Appleby and Anastas' (1998) six principles for affirmative therapy, which focused on the individual client-provider interaction. Crisp's Gay Affirmative Practice Scale (2005) focuses on individuals' beliefs and practices rather than organizational or broader structural practices such as developing inclusive hiring policies and advocating for social change (Mullins, 2012). Recommendations for affirmative therapy with sexual minorities (developed as early as 1991) focus mainly on the therapeutic relationship (Bridges et al., 2003). LGBTQ-affirming service environments and service provider-client interactions have been typically captured through discussions of cultural competence in nursing, medicine, and other health contexts (Australian Medical Association, 2002; RNAO, 2007). While some resources (e.g., City of Toronto, 2008; RNAO, 2007) focus on both the individual and organizational context, others are limited to individual provider-client interactions (e.g., Garrett \& Barret, 2003).

Positive space, a term which appears more in Canadian sources rather than those from the United States or United Kingdom, as we use it in this article, addresses inclusive environments that support both LGBTQ clients and employees. Positive space campaigns, such as one that began at the University of Toronto, Canada, in the mid 1990s, are now visible on many Canadian university websites and in college and university reports about campus climate (Rankin, 2007; Valentine et al., 2009). They aim to foster inclusive higher education environments and a climate "free of discrimination" for faculty, staff, and students. According to OPHA (2011), a Canadian group that has advocated for LGBTQ-inclusivity across communities and sectors beyond the public health sector, 
Positive Space refers to an agency that is open and welcoming, as well as equitable and accessible to persons of all sexual and gender diversities, both to clients and employees of the agency. The term also refers to an agency in which all staff have been trained to understand the issues around sexual and gender diversity and are familiar with human rights, diversity and resources. (p. 33)

The literature aligned with the positive space concept draws attention to the dominantly heterocentric or heteronormative nature of health and social services and the need for organizations and their providers to convey affirming messages for diverse LGBTQ clients and workers (Buddel, 2011; City of Toronto, 2008; Martinez, Barsky, \& Singleton, 2011), those that move beyond conveying notions of "tolerance" or "acceptance" which in effect reflect negativity (Canadian AIDS Society, 1991; Biaggio et al., 2003, p. 548). The notion of positive space reflects the importance of affirming the human rights of LGBTQ people to self-determination as well as strategies for challenging organizational and social invisibility and marginalization of gender and sexual minorities, such as developing inclusive programs, services, and policies. More recently, the unique issues of bisexuals and trans people in health and social services in "LGBTQ" health, Two Spirit, intersex, queer, and questioning people are considered in creating inclusive environments, sensitivity to diversity within these groups, and the meaningful involvement of LGBTQ people in the change process (Dobinson et al., 2005; Gapka et al., 2004; City of Toronto, 2008; Johnson et al., 2008; Mottet \& Tanis, 2008; Positive Space Network of Halton, 2014; Singh, Meng, \& Hansen, 2013). Over the past decade, comprehensive transgender-affirmative practices that address the organizational and policy context have emerged (Bauer et al., 2007; Finkenauer, Sherratt, Marlow, \& Brodey, 2012; Gapka et al., 2004; Mottet \& Tanis, 2008). Clinical resource material, posters, and human rights policies that explicitly include diverse LGBTQ people contribute to welcoming environments, as do service providers who ask questions about sexual orientation and gender identity in their interactions with clients (Crisp, 2005; Institute of Medicine [IOM], 2011). Barriers to accessing programs and services can result when LGBTQ people have experienced discriminatory, hostile, or less than welcoming interactions with service providers or do not see their needs reflected in programs or services. Interactions which stigmatize, pathologize, and/or stereotype queer and/or transgender people, or in which the provider rather than the client controls how and whether this aspect of clients' lives is taken up in care, contributes to barriers. Dynamics such as these can influence LGBTQ people to be hesitant to disclose their sexual orientation and gender identity to service providers or to avoid services completely (Mulé et al., 2009).

This focus on creating inclusive environments is a timely topic given the signficant health and social science literature that has emerged over the 
past decade addressing cultural competence in professional curriculum and service organizations (e.g., Daley \& MacDonnell, 2011; Jackson, Johnson, \& Roberts, 2008; MacDonnell, 2009; Mulé et al., 2009; Wilkerson et al., 2011). For the most part, this focus on diversity has traditionally called for individual practitioners to celebrate or be sensitive to cultural differences in their patient/client populations. It has often implicitly or explicitly focused on visible differences related to race or language, supporting a multicultural and/or diversity discourse (Daley \& MacDonnell, 2011). At the same time, there is an increasing, but still limited, literature that accounts for intersectionality in relation to LGBTQ people (e.g., Brotman, Ryan, Jalbert, \& Rowe, 2002; Eliason et al., 2010; Ryan, Brotman, Baradaran, \& Lee, 2008). Without attending to the sexual and gender diversity relevant to diverse LGBTQ people, such approaches can exclude and marginalize LGBTQ people and their health issues, and they are limited in their capacity to foster practitioners' capacity to create welcoming and inclusive environments for the diverse groups they serve.

Over the past two decades, research has pointed to comprehensive approaches for creating inclusive social and health care (Daley \& MacDonnell, 2011). A variety of LGBTQ-focused clinical guidelines and stand-alone service recommendations and policies and practices which contribute to affirming organizational spaces for gay men, lesbians, and trans people have evolved. These have been developed mainly in the United States, but also in Australia, the United Kingdom, and Canada (e.g., City of Toronto, 2008; GLMA, 2006; Hudspith, 2001; Kaiser Permanente, 2000; Leonard, 2002; Makadon, Mayer, Potter, \& Goldhammer, 2007; McNair \& Hagarty, 2010; NHS Inclusion Project and Stonewall Scotland, 2005; OPHA, 2011).

In 1999 the GLBT Health Access Project (2010) linked specific measureable indicators to each of 14 standards of practice to foster LGBTQ-affirmative care. ${ }^{2}$ A decade later, the Public Advocate for the City of New York (2008) referred to that project as one of four resources for developing "quality indicators, best practices and LGBT-inclusive healthcare targets" (pp. 15-16), including The Healthcare Equality Index (GLMA and the Human Rights Campaign Foundation, 2014) and Healthy People 2010 Companion Document for LGBT Health (GLMA, 2001). ${ }^{3}$ While these documents differ in focus and purpose, all documents identify organizational policies and practices such as LGBT-focused health provider training and LGBT-inclusive policy development as integral to affirmative care.

Nevertheless, while LGBTQ access has been emerging as relevant in a number of health and service sectors such as hospital, long-term care, and public health, there is an absence of LGBTQ-focused literature on the home care setting (Daley \& MacDonnell, 2011). This article focuses on the first phase of a research study in Ontario, Canada, which aimed to understand issues relevant to home care service providers, LGBTQ service users, and other home care stakeholders with an ultimate goal of fostering LGBTQ-inclusive 
care in the home care sector. Elsewhere, we have detailed the findings of the first aspect of this two-pronged phase, a critical discourse analysis of access and equity literature and policy documents (Daley \& MacDonnell, 2011). The second aspect of this phase, the focus of this article, concerns interviews with practitioners and administrators in the field. The purpose of this phase of the project was to gain insight into the development of LGBTQpositive space in such organizations in the Greater Toronto Area (GTA) in Ontario, Canada. Toronto is a vibrant city which is home to a diversity of ethnoracial and immigrant communities and one of the three largest cities in Canada, along with Vancouver and Montreal, with well-established LGBTQ communities.

\section{METHODOLOGY}

An exploratory qualitative design was chosen for this KI research. Our focus was to understand dynamics that shape positive space and to uncover how this played out over time in various organizations as described by KIs working in the field. This qualitative study, using purposeful sampling, was not intended to be generalizable to all organizations, but to create understanding about organizational change related to the development of LGBTQ-positive space in an urban Canadian context. It offers insights into these processes from the perspective of diverse actors in community-based health and social service agencies in the GTA.

\section{Sampling}

Purposeful sampling was used to recruit KIs who were interested and able to share information about the process whereby positive space developed in their agencies. KIs in 12 organizations in the GTA which were known as being LGBTQ-positive were approached by the researchers by e-mail or by phone about their interest in participating. KIs in these agencies were known by the researchers through community LGBTQ networks and activities such as conference presentations about their interest in LGBTQ issues and development of positive space. In two cases, the agency identified a KI. All KIs approached were chosen for their insights into agency development of positive space. Maximum variation sampling (Morris, 2006) was used to include a range of health and social service agencies to represent diverse sectors (primary care, mental health, community, and hospital), conditions, populations/communities across ages (racialized groups, including immigrants, Two Spirit people, adolescents, people living with AIDS, people with disabilities). We aimed to learn from agencies in sectors that have already been quite involved in creating LGBTQ-positive programming in the region. 
Data collection took place in 2009-2010. We received ethical approval from the researchers' university research ethics board before starting recruitment. Of the 12 KIs approached about participating in this study, eight agreed to participate. KIs were provided with information about the informed consent process. The following aspects of informed consent included on the written consent form were discussed with all KI participants verbally as part of the informed consent process: the study purpose; the nature of study participation; and risks and benefits of the study for potential participants. Potential participants were informed of the voluntary nature of study participation, and told that they could withdraw from the study at any time and could opt out of answering any interview questions. Information was provided about remuneration and about protecting both KI and organizational confidentiality. For instance, in reporting of findings, no names of organizations would be divulged; nor would information about the sector and the nature of the agency population focus, for instance, in a way that could potentially identify an agency. Interviews occurred as providers in their paid roles; no honorarium was provided. Several KIs were known to some members of the research team, but none were working colleagues; the voluntary nature of participation was stressed. After participants signed informed consent forms, they completed 90-minute in-depth semi-structured interviews conducted by one or two interviewers. The interviews were digitally recorded and transcribed verbatim for analysis. Transcribed interviews were anonymized.

Questions focused on dynamics which would offer insight into the histories, challenges, and turning points which shaped the development of LGBTQ-positive space in the organizations. We asked, "What would it take to create positive space?" and "How has it played out over time and place in agencies in the GTA which are known for LGBTQ-positive services?" The questions asked reflected the researchers' engagement with access and equity literature from a previous project (see Appendix for interview guide). Since our study focus was organizational policies and practices rather than the KIs themselves or the subjectivity of the speaker, we did not collect demographic data on the KIs. In retrospect, this was a limitation of the study and would have been useful in contextualizing the data when reporting findings.

\section{Data Analysis}

Given the exploratory nature of the research and the study purpose to describe the phenomenon of organizational accounts of creating positive space (which has not been well-documented), conventional content analysis (Hsieh \& Shannon, 2005), as an inductive approach to analysis, was used. This is a method "for the subjective interpretation of the content of text data through 
the systematic classification process of coding and identifying themes or patterns" (Hsieh \& Shannon, 2005, p. 1279). In our application of this method we used a critical lens approach that aims for understanding of a phenomenon in a way that can foster social change. A critical lens draws attention to the ways in which relations of power shape our social worlds, and the approach accounts for relevant historical, economic, political, social, and cultural contexts in relation to the inquiry (O'Connor, Denton, HajdukowskiAhmed, Zeytinoglu, \& Williams, 1999). Thus, for instance, intersectionality (i.e., dynamics of gender, sexuality, race, and class and their intersections) is considered relevant to fostering equitable access to care (Hankivsky et al., 2010).

As researchers using a critical, intersectional approach, our assumptions influence data collection, analysis, and reporting to yield a partial, contextualized understanding of the phenomenon under study (Morris, 2006). We acknowledge that participant narratives are co-constructed during the interview process through the participant-researcher interactions. Rather than a structured set of questions which might limit the breadth and depth of participant responses, a semi-structured interview guide along with openended probes were used to allow for a fulsome understanding of issues discussed (Hsieh \& Shannon, 2005). During analysis, while we were mindful of allowing codes to emerge from the data (Hsieh \& Shannon, 2005), we acknowledged that our prior engagement with LGBTQ-focused access and equity research and the concept of heteronormativity informed our analysis. Throughout our analysis we used strategies for rigor such as making explicit reflexive notes about emerging themes and peer debriefing to account for bias in this process (Morris, 2006).

In this article we refer to "dimensions" of "positive space" or "organizational practices, policies, or strategies," rather than indicators of positive space. On one level, we were interested in organizational practices that could eventually be used by home care agencies to develop measurable program or organizational "indicators" (such as associated with the GLBT Health Access Project [2010] discussed earlier). However, our interest at that time of the interviews was focused on learning about processes of organizational change identified by KIs rather than measurable indicators per se. In retrospect, asking a question about measurable indicators or useful tools with examples from the access and equity literature may have been useful to understand tools or guidelines that KIs/organizations used in developing positive space.

Two researchers independently coded the transcripts, initially reading over the transcript as a whole for immersion in the data and subsequently conducting line-by-line coding which yielded an initial coding scheme of 94 "codes" organized in 18 emergent categories (Hsieh \& Shannon, 2005). ${ }^{4}$ Analysis entails analyzing data for patterns in the ways codes and emergent categories are linked and revising categories as needed to group them 
into meaningful clusters or macro-themes with associated subthemes that contribute to an understanding of the phenomenon under study (Hsieh \& Shannon, 2005). The two researchers began the process by sharing their initial coding of the 18 categories and associated 94 codes, using discussion and returning to the transcripts in an iterative fashion until a consensus process was reached about the final macro-/subthemes. Ultimately six macro or overarching themes emerged:

\section{Community Engagement/Partnerships;}

2. Programs and Services;

3. Organizational Processes;

4. Leadership;

5. Education/Training; and

6. Challenges.

These themes and their associated subthemes are reported in the Findings section. As would be expected in semi-structured interviews, the narratives focused on some topics more than others, such that some, but not all, macro-themes have several subthemes. For instance, the first macro-theme, Community Engagement/Partnerships, is a stand-alone theme, whereas the second, Programs and Services, encompasses three distinct subthemes: access, relevance, and visibility.

Our examination of narratives for codes, categories, and themes was informed by our familiarity with access and equity literature such as how organizational policies and practices contribute to positive space (e.g., examination of agency policies, intake forms, and hiring practices). We took as a starting point that all social institutions are shaped by heteronormativity, which can oppress and marginalize diverse LGBTQ people. As the analysis unfolded, it reflected the ways in which intersectionality was relevant. Several of the final overarching macro-themes which reflect a focus on organizational processes and practices also account for participant talk about intersections among gender, sexuality, racialization, and other social difference. In an early phase of our analysis, we captured intersectionality under codes such as that addressing "anti-oppression (AO) practice," a philosophy that uses a critical lens to address power and privilege. Table 1 lists relevant initial codes and categories that consider either intersectionality or AO, which represent how participants addressed intersectionality and/or AO practice in relation to how social difference and their intersections are visible and/or taken up in organizational philosophy/mission statements, written policies (e.g., hiring), and equity councils that aim for broad representation from equity-seeking groups. Intersectionality and/or AO were embedded in all themes that addressed education/training and organizational challenges of implementing AO given agency mandates and funding to provide services for specific populations/cultural groups. Reporting of the final macro-themes shows how 
TABLE 1 Initial Codes: Intersectionality/Anti-Oppression (AO) Lens

Category Initial Code

\#2 Philosophy/Mission

\#4 Policy

\#5 Equity
Programming/Structures

\#7 Hiring

\# 14 Intersections: Working Across Differences
- Developing organizational anti-oppression (AO) philosophy

- AO "as part of the fabric"

- Social determinants of health (SDOH)

- Making diversity a formal core value

- Identifying priority populations

- Formalize AO framework vis-à-vis developing written policy

- HR hiring policy; HR policy for transitioning(ed) staff

- Positive space policy

- Complaints protocol

- Client rights and responsibility policy

- Establishing diversity/equity office

- Developing a diversity committee/AO council

- Affinity committees, caucuses

Queer Staff:

- Hiring "out" queer staff (frontline, management, senior management)

- Creating a dedicated team of professionals for LGBT people; developing LGBT dedicated team

- Advertising for queer staff; recruiting queer staff; opening doors to queer staff

- Procedures to hire queer staff; integrating LGBT into hiring processes;

- Focus beyond technical skills toward process skills in hiring; using situational questions to assess AO skills

- Creating safe space for queer employees; safety for queer staff; organizational support for queer staff

Equity Staff:

- Dedicated equity staff

- Hiring at director level; full-time equity director

- Acknowledging and recognizing complexity of differences

- Acknowledging authority of voices/who can speak on behalf of whom

intersectionality was relevant to $\mathrm{AO}$ approaches to education/training and a core organizational value. It also presented a key organizational challenge. Participants stressed there were everyday challenges to keeping intersectionalities and power and privilege on the radar, as they worked to put AO into everyday practice. 
TABLE 2 Organization's Population Focus

Racialized population focus (newcomer,

$$
\begin{aligned}
& N=3 \\
& N=2 \\
& N=3
\end{aligned}
$$

Two Spirits, Black communities)

Age-related population focus (youths,

Broad population focus related to sector-specific mandate

(primary/health care, mental health, families)

Total $N=8$

Descriptive data in participants' narratives about the nature of the organizations and elements of change processes emerged. As participants reflected, they often identified key turning points that shaped the iterative steps toward the development of positive space. Codes, categories, and themes captured these emerging insights, dynamics that were unique to particular organizations as articulated by individual KIs, as well as those common among organizations, themes that pointed to barriers for service and related organizational policies and practices for LGBTQ people.

\section{FINDINGS}

Sample

The characteristics of participating organizations varied considerably. To maintain confidentiality of participating KIs and organizations, general information is provided about the sample. Agencies ranged from small, singlesite through large multisite organizations, those located in downtown with a narrow local catchment area compared to those in suburban Toronto. These agencies/organizations are well-known as either LGBTQ-specific agencies or as those currently providing LGBTQ-positive programs in Toronto. They represented diverse sectors (primary care, mental health, community, hospital), populations/communities across ages (racialized groups, including immigrants, Two Spirit people, adolescents, people living with AIDS, people with disabilities). Organizations were fairly evenly divided in relation to having a population focus on racialized, age-related, or broad populations. For the purpose of reporting, we grouped agencies in relation to their population focus (see Table 2).

As noted earlier, since our study focus was organizational policies and practices rather than the KIs themselves or the subjectivity of the speaker, we did not collect demographic data on the KIs, which in retrospect would have been useful in contextualizing the findings. However, interview transcripts did provide some information about the KIs. The KIs represented 
diversity across gender identity and queer identities with the majority representing minority sexual locations and a spectrum of ages, from a few in their twenties and thirties to those who were older with more than 40 years of professional practice experience. Several were members of racialized groups. These LGBTQ-identified providers and allies reflected two who had more than 10 years of involvement with their agencies and those whose insights were based on more limited employment there. Over the course of their careers, a number of these KIs had been engaged as frontline practitioners, as well as program coordinators or administrators, including director roles, in these or other organizations. A number held social work credentials. Participant narratives also reflected insights gained from related equity work in the health and service sectors. To provide some organizational context in reporting of findings, while maintaining confidentiality, the nature of the organizational focus is provided when direct quotes are cited.

In this article we report on the six overarching themes which emerged from analysis. We begin with an overview of dynamics that shape agencies and select several that relate both to the process of developing positive space in these agencies, such as leadership, often cited in the literature as an important dimension to foster access and equity. In the Discussion section, we then identify several discourses that reflect strategies for creating positive space in health and social service agencies. We situate these findings in the literature. We cite narrative excerpts that represent all eight KIs, using numbers to identify them in order to protect KI and agency identities. In order to provide organizational context, we also identify the KI organizations by their population focus.

\section{Overview of Dynamics Shaping Agency Practices}

What became evident during the project was that recording organizational histories from the perspective of KIs was, in itself, important as historical insight and institutional memory, given the staff turnover at these agencies and given a number of the KIs who are retiring or moving into other fields/organizations. For several KIs, their work in relation to developing positive space was part of their broader commitment to political activism linked to social movements that may be aligned with social work and community health nursing.

Although all of the participating agencies are known as being LGBTQinclusive, KIs note that there is much work to be done to sustain and further develop current initiatives in their own organizations and in the health and social service sector more broadly. Despite the advances made in human rights legislation, visibility of same-sex marriage, and transgender issues in mainstream media in a Canadian context, a number of KIs stressed that silos remain in health and social services. As one KI notes, there are still assumptions that mental health, counseling, and sexual health are the "place" 
for LGBTQ health and these assumptions limit the recognition that a LGBTQ focus is relevant to agencies and their staff/providers as a whole. Even within these domains of practice, significant numbers of practitioners and administrators lack awareness of LGBTQ health and service barriers. For instance, a KI recently presented on queer and trans (LGBTQ-focused) issues related to mental health at a regional conference and many attendees asked, "What does LGBTQ stand for?" (\#6, age-related population focus).

These narratives of KIs were rich with examples of the numerous factors that shaped the creation of positive space within their respective organizations. For the purposes of this article, we explore six key themes that are related to the process of creating positive space:

1. Community Engagement/Partnerships;

2. Programs and Services;

3. Organizational Processes;

4. Policies;

5. Leadership; and

6. Challenges.

\section{Community Engagement/Partnerships}

Working in partnership with other people because everything we do will sort of benefit everybody. So... it's joining other people to do what we do. (\#7, broad population focus)

For the most part, it was evident that these agencies placed a priority on engaging with LGBTQ communities with a recognition of the empowering potential of enhancing LGBTQ voices and visibility-as an ethical imperative. As one KI indicated, "Community engagement... helping people understand their rights, giving people confidence, all of those things that build an empowered community..." (\#7, broad population focus). KIs described respecting communities' insights into agency/community assessments and thus for identifying gaps in LGBTQ service planning and delivery, at times using a community development approach (\#1, age-related population focus). Organizations sought community member input through community soundings and needs assessments, not just responding to community input, but developing and forming community partnerships (activist/advocacy groups, community-based services, provider agencies, policy bodies, programmers, allies) and relationships with health and social service policy bodies (e.g., Rainbow Health Ontario). They took steps to formalize partnerships and/or worked in other ways with community partners, forging longterm relationships which showed the value of community input that was not just for the benefit of a one-off needs assessment, but was integrated into 
organizational functioning. Such a commitment to community involvement prompted a variety of initiatives: "We have undertaken to have a very open dialogue about what is wrong with services and to try to communicate that we are looking at a whole new change initiative" (\#4, broad population focus).

Participants viewed community partnerships and engagement as a desirable focus, which included internal and external communities, academic/community relationships or community-based partnerships based on common goals and, at times, strategic decisions. As one KI noted,

So, we had to make those kinds of tough decisions around who we were going to work with, right? And how they were going to respect us as gay and lesbian people, right? So that was very challenging too to go through that learning curve. ( $\# 8$, racialized population focus)

Another indicated the following:

We have a partnership with [LGBTQ-community-based organization]... and that program is much more community based.... We have a lot more in common, we do a lot more work in the community, we kind of get that whole-those pieces—so it was nice to have some allies in that. (\#6, age-related population focus)

These partnerships offered opportunities to share scarce resources, especially for small organizations, and build on respective strengths. A KI offered the following:

Community cooperation around the people who had the... ability to do the proposal writing and those kinds of expertise... right, but when it came to implementing those things... then we needed to do some more outreach to our community. (\#8, racialized population focus)

\section{Programs and Services}

Three key dynamics that informed key informants' discussions of programs and services were access, relevance, and visibility.

\section{ACCESS}

It was evident that groups within LGBTQ communities and agencies were asking tough questions about gaps in access for diverse lesbians, gay men, bisexuals, and trans people. As one KI shared, 
I think it is kind of cool they didn't say, "Why are there no GLBTQ people coming here?" Because they knew that wasn't the issue, right? So they said, "Why aren't people coming out? What is it about this place that makes people not feel comfortable in here?" (\#6, age-related population focus)

They spoke of multiple strategies that would reflect the welcoming environments needed to enhance access for vulnerable clients.

You don't have to spend a lot of money... when people come into the building they see that artwork that is being done by the person in the transgender group... and it is there in a physical way so that is part of setting that space... so physical space is part of the safe space thing and emotional safety is a part of that space piece. ( $\# 2$, racialized population focus)

Another stressed the following:

There's always that flavor of, you know, you have the right to things, we'll work with you, we'll support you, we'll teach skills... we'll help you build communities so that you're not isolated and alone. (\#7, broad population focus)

They noted the credibility that health and social service agencies have within LGBTQ communities when they offer consistently high-quality care. A KI noted the following:

You have to go that step of actually making a protected place where people can be really confident that this is where they're going to get a certain kind of care with certain kinds of well-trained sensitive providers. (\#7, broad population focus)

For most organizations, a focus on transgender issues was a relatively new challenge that, at times, was prompted by trans people's actions to address their invisibility in programming. "The transgender community... led to our non-discrimination policy" (\#8, racialized population focus).

\section{RELEVANCE}

Participants spoke of the value of dedicated LGBTQ-specific programs and services and the need for all generic programs and services to be inclusive of LGBTQ people. As one KI remarked, "... you need population-specific programs and you need to build the clinical capacity in your generic programs" (\#7, broad population focus). This required developing queer-specific programs and projects and population-specific programs (e.g., LGBTQ seniors) 
and pushing for LGBTQ dedicated space, processes which happened incrementally. These successes were not taken lightly. As this KI noted, "I think there's something more than symbolic about [dedicated space]" (\#7, broad population focus).

VISIBILITY

KIs described LGBTQ visibility in multiple ways:

It was partly about saying we're here and we're open... a visibility that would mean that you didn't have to be well connected or you didn't have to know. It would just be there in the phone book or on a website or on a poster and sort of no hiding. (\#7, broad population focus)

As another one noted, their agency historically had a reputation for being safe and queer-positive but then made a conscious decision to "put queership... on the forefront of issues that we were addressing as an organization... people who didn't know where to go came to [us]" (\#3, racialized population focus). In addition to enhancing access, KIs reflected on how culturally specific services that reflected gender and sexual diversity were integral to inclusive care:

When I wanted to portray us as in this day and context of who we are, that was our first step in sort of telling everybody across Canada this is who we are, right? So in the poster [with its focus on cultural diversity within LGBTQ communities], I still have a copy on the wall." (\#8, racialized population focus)

When LGBTQ staff were visible in an agency there were positive consequences for client disclosure: "Once we started having more out staff, more youth did start coming out... especially youth from those [ethnic minority] communities" (\#6, age-related population focus). As another KI indicated, this visibility is fraught, given the multiple stigmas of HIV and same-sex identity which continue to shape their agency's engagement with partner agencies, although there are slow signs of progress. Building organizational capacity was often linked to building community capacity: "We have hired people that were our clients and now they are part of our groups to be peer facilitators and that's been a whole other interesting thing to do" (\#6, age-related population focus). 
Given the range of agencies and histories, it is not surprising that KI narratives reflected a variety of organizational approaches to creating positive space. Although all considered community engagement a priority, policy development processes varied in their timing during their organizational histories and included formal and informal as well as top-down and bottom-up approaches. Several KIs spoke of the ways in which their agencies practiced according to principles of equity and anti-oppression (AO) philosophies in which diversity was implicitly a core value, but for the longest time had no such written policies in place.

Structural influences such as agency alignment with health policy decision makers and funders (e.g., local health authorities) and the requirements of employment policy (e.g., affirmative action) and accreditation bodies influenced these organizational priorities and trajectories with respect both to the development of positive space and policies that explicitly address LGBTQ people. Some agencies worked with a service delivery model that was more medically or clinically focused, while others had mandates which aligned more clearly with a focus on the social determinants of health and this shaped programming and service challenges and opportunities. Several agencies noted challenges to identifying LGBTQ people as priority populations, especially those whose mandates were to serve specific cultural groups, as described by a KI from such an agency:

So you're a new group, you know, your focus is over here and then, you know, your funding says you have to do this and we had to do a little bit of shifting and focusing and that took a numbers of years. (\#8, racialized population focus)

Another KI shared the realities of the early days:

It was a rocky beginning because it was a mainstream organization that did not really know how to deal with or respond to or integrate a fairly politicized, as well as a marginalized group, so there were some very quick misunderstandings and misses in communication. So, the agency then... put together a... task force compiled of board members, staff, and management to hammer out more tightly some policies and practices that needed to be observed. (\#5, broad population focus)

Certainly, the availability of stable, core funding for LGBTQ programming was linked to agency directions and priorities at different points in their organizational histories. One KI suggested the following: 
Very often it starts with training and... goes into more structural sort of supports... we did it backwards. We looked at organizational context and then developed training based on the information that we had. (\#4, broad population focus)

However, others began with a strategic plan that centered the development of a philosophy or mission statement which either included AO philosophy or a broad diversity lens.

There was a group comprised of... [organization's members] and some community members in... a transition group [who] looked at what kind of services were needed, how to structure the services, what [the] values and principles vision and mission would be. (\#5, broad population focus)

\section{ORgANIZATIONAL ASSESSMENT}

Organizational assessment processes described included conducting an environmental scan, identifying need for capacity building, conducting an inventory of $\mathrm{AO}$ practices, getting an organizational baseline, and having a dedicated staff position for needs assessment and producing recommendations. For larger organizations, equity programming/structures were created. These included the establishment of a diversity/equity office, diversity committee/AO council, and/or affinity committees and caucuses. Even in smaller agencies, there were opportunities to support equity as noted by one KI who described a progressive manager's efforts to create processes and structures that would serve the agency well for years:

My manager... had done kind of a look within the agency around diversity... in terms of staff, clients that would come here, what communities' needs it was serving and wasn't serving. . . from that they started a diversity committee. (\#6, age-related population focus)

\section{POLICY}

The types of formal written policies KIs described as relevant to operationalizing AO philosophies included human resource hiring policies, complaints protocols, client rights and responsibility policies, and positive space policy. One KI linked policies for transitioning employees (those involved in gender transition) to both employee and client safety: 
... we needed to have a plan and also people make complaints. What were we going to do, you know? Who was going to handle it? Who was going to talk to these families if they were upset about this?... [But]... nothing has been written down here. (\#6, age-related population focus)

In terms of hiring, KIs spoke of the need to hire out queer staff across all levels, creating a dedicated team of professionals for LGBTQ people; developing LGBTQ dedicated teams, advertising for, and recruiting LGBTQ staff; and integrating LGBTQ-relevant issues into hiring processes, using situational questions to assess AO skills. The need for safe space and organizational support for LGBTQ employees was also noted. As a KI indicated,

I also felt that having a dedicated team and people who are hired specifically because they wanted to serve these populations would build a higher level of [organizational] commitment and skill and leadership. (\#7, broad population focus)

Making Anti-Oppression Philosophies Work in Practice

A recurring theme throughout KI narratives was the "thick" language of anti-oppression and how to demystify it to make it accessible in practice for all staff, clinicians, administrators, clients, and community partners. KIs spoke of strategies such as examining intake forms for heterosexist language and the significance of a workplace plan for staff who were involved in gender transition processes. Another noted that explicit policies that address both sexuality and racism "have reduced major issues of homophobia and transphobia" (\#3, racialized population focus). Although one KI suggested that "It's a daily conversation... it is quite part of the fabric, I would say, and if you sit and talk about anti-oppression, nobody sort of looks at you weirdly" (\#7, broad population focus), others noted that the language of "diversity" or access and equity" was more accepted in their agencies. However, even with solid agency commitment and organizational structures in place, KIs noted that things are not all smooth sailing:

Sometimes I think there have been times where there's been some struggles and hurt feelings along the way... it kind of backs off a bit and then... you start getting things working again. (\#7, broad population focus) 
... Openly queer people in other positions of leadership helps because it all gives credibility and support... is protective. (\#7, broad population focus)

Participants spoke of the notion of shared, distributive, or participatory leadership. This "strength in numbers" (\#6, age-related population focus), as one KI phrased it, is the sharing of leadership between two or more individuals and across levels of an agency or organization which includes processes characterized by the coordinated efforts of many people to provide an agency with impetus and direction (Spillane, 2006). In effect, leadership on a project is distributed across a broad base of employees with each having distinct and different responsibilities that contribute to the overall success of an agency as well as particular initiatives. This idea of shared or distributive leadership is contrasted with a traditional notion of leadership whereby one person is positioned at the head of a group, directing, teaching, and encouraging them. The KIs described initiatives guided by this traditional notion of leadership as personality-dependent initiatives and problematized these initiatives in that when the person left the organization the initiative died. Shared leadership is an attempt to avoid this situation and to develop leadership processes and structures that maintain and sustain initiatives.

Key to this was the notion of leadership and governance with champions at multiple levels of organizations, including board of directors, frontline staff, management, and volunteers. Buy-in at the board level was integral to moving forward as an agency, understanding the complexities of what LGBTQ inclusivity would entail, and sustaining this momentum over time.

The board wanted to ensure that there were GLBTQ people on the board... there was some balance at the upper level of the organization. At the leadership level there was someone who... had some power, enough of a voice to push things that needed to happen... the board today still works to have representatives that reflect our clients. ( $\# 5$, broad population focus)

[In] senior positions, either queer people or people that really supported this work... has made I think a huge difference and they've given us a lot of room to keep applying for grants and coming up with new ideas. (\#6, age-related population focus)

However, KIs also described leadership processes that spread decisionmaking authority throughout the agency, creating a "flatter," more representative governance structure. As one KI noted, 
We've had strong staff leadership_outstandingly wonderful people... great colleagues and they have taken advantage of training and opportunities, successful in getting funding and serving a highly underserviced community. (\#1, age-related population focus)

KIs cite as examples the use of an advisory committee/network/council made up of staff at all levels, patients/clients, volunteers, and members of the community, including allies, to address issues of diversity, by establishing LGBTQ employee networks - and providing structured leadership opportunities for all stakeholders. They spoke of the need to offer mentoring opportunities for staff, who have historically been left out of leadership positions, as one KI described it: "Developing a... cadre of leaders... you know, at more ordinary levels of the organization... is really essential for us to sustain it" (\#4, broad population focus).

\section{LEADERSHIP FOR ADVOCACY BEYOND THE ORGANIZATION}

KIs also spoke of shared leadership as occurring across organizations, not only within organizations. This is particularly relevant when thinking about systems advocacy initiatives-for example, how shared or distributive leadership is useful to sector-specific agencies and organizations, such as mental health, settlement, or health service providers-in relation to obtaining the resources (e.g., training resources, research) required to address disparities in access for diverse LGBTQ communities. A KI noted his or her reliance on "volunteer leadership who had a long history of advocacy at the Ontario-wide level" (\#1, age-related population focus), Another indicated the following:

One of the things [we] as an organization have been very active [at] the table sort of at a systems level... [is] trying to convince the LHIN's [Local Health Integration Network] that [health equity] needs to be on the agenda... like collateral with other folks, so that sort of systems-level advocacy. (\#4, broad population focus)

\section{Education/Training}

\section{Training Content and Processes}

These participants echoed others in LGBTQ communities who call for mandatory LGBTQ training initiatives that would increase awareness of language issues, health disparities, and intersectional dynamics relevant to diverse LGBTQ groups. Their narratives included discussions of conducting staff training, developing a core curriculum and developing training capacity, train-the-trainer programs, and sharing LGBTQ knowledge within the 
organization on informal and more formal bases to build higher levels of commitment, skill, and leadership.

Three dimensions of education/training emerged in these narratives. Certainly all KIs agreed that ongoing education was an integral component of creating more inclusive organizations. However, their narratives emphasized the following elements.

Anti-oppression lens. Throughout the narratives, KIs drew attention to the importance of focusing on power and privilege in everyday organizational practices. The use of an $\mathrm{AO}$ lens with attention to intersectionalities of sexuality, gender, race, and ability was often described as crucial, but often bringing challenges. One KI stated the following:

We asked a lesbian and gay man of colour to actually come in and do a... one-day training looking at diversities in the queer community itself, so trying to blend those two very active features [anti-racism and LGBTQ work] that were happening around the agency in those days.... (\#5, broad population focus)

Embedded in functioning. In addition to orientation and in-service, KIs offered insight into the everyday nature of education and training that addressed clinical practice and employment bias. One KI noted, "It is a broader education across marginalized groups and how bias creeps into how we do business that is a mandatory training for managers" (\#4, broad population focus). For all agencies, mandatory training applied not just to staff or clinical personnel, but board members and volunteers. Yet as a KI stressed,

There needs to be a passion for it. It needs to be part of the fabric of the organization... a lot to it more than just staff training... getting it into the culture of the place... [can be] very difficult. (\#1, age-related population focus)

As an example of how that can play out, another KI shared the following:

We used to actually practice it in staff meetings... have little skits where people could demonstrate how you could talk to somebody about using a word that was maybe discriminatory. (\#7, broad population focus)

Inside/outside. Participants described dynamics such as the need to have allies on board within the organizations reflecting well-documented inside/outside dynamics in LGBTQ health that focus on who might represent LGBTQ communities' experiences and knowledge. However, the inside/outside theme moved beyond this. In addition to working within their organizations to create more inclusive functioning, most KIs identified the 
need to work with community partners as well, for instance by developing training material/tools for providers/agencies. As a KI noted,

It's difficult to do anti-oppression work. . . if you don't keep feeding yourselves by linking you [sic] with others and in turn supporting them... we have continued that back-and-forth with other community-based organizations for the most part and it has been very rich. (\#7, broad population focus)

In fact, for some agencies, partner commitments to positive space or $\mathrm{AO}$ philosophies were determining factors in sustaining partnerships. "We worked with [a non-LGBTQ agency]... because a lot of our transgendered people would visit their organization. .. so we had to do some real sensitizing training with them and their staff" (\#8, racialized population focus). Another layer was organizational engagement in external capacity building; educating other agencies (conferences, workshops, tools) and educating government, working at policy level, political processes that these KIs and agencies deemed integral to enhancing material supports for diverse groups within LGBTQ communities.

\section{Challenges: Mandates, Funding, and Resources}

Participants noted that the organization's original mandate for programming and services, as well as funding, drove the direction of agency priorities and programming at different points in the life of the organization. Mandates to promote health, well-being, and quality of life of their clients varied for a handful of agencies with the original mandate being LGBTQ-specific; for others a specific cultural group was named, and for some their mandate included education of the larger community. The availability of funding and staffing for all agencies influenced resource development for staff training, developing programs and flyers and perceived opportunities to collaborate with other partners on projects that could explicitly focus on LGBTQ issues or groups.

\section{INCONSISTENCY ACROSS ORGANIZATIONS}

Agency dynamics reflected challenges of shifting cultures given the heteronormativity that marks all social institutions. KIs considered contributing factors, including the overt association with sexuality that marks LGBTQ health work: 
uality, bringing EXTRA [LGBTQ newspaper] into a waiting room was a whole different ballgame whereas before it would never ever appear in the agency and so that was a culture shock. ( $\# 5$, broad population focus)

As one KI reflected, "We had to deal with homophobic bureaucracy and it was not easy in those days" (\#8, racialized population focus). Yet various KIs remarked on current settings that reflect both "being welcomed with open arms" (\#6, age-related population focus) and "toxic pockets in the organization" (\#4, broad population focus):

And we would meet off-site to talk about some crappy things that were going on and just, you know, you'd go to the [staff] room and all you'd hear is like, "Oh, my husband this" and "My wife this" and it was just so straight... I stopped going. (\#6, age-related population focus)

One noted, "But there really are mixed feelings about [population-based teams]. . . at different levels. . . and I think it just comes from people's different philosophies or different backgrounds" (\#7, broad population focus). From the KI perspectives, union contexts both enhanced a focus on equity and contributed to barriers. Another remarked,

... I want to have staff of the community who deliver a critical service because they know the community but I am required to interview people that know nothing about the community because they have seniority... makes it difficult around any marginalized group.... It can slow processes a lot. (\#5, broad population focus)

\section{COMPETING PRIORITIES}

KIs also noted that "there are just other tensions... times when we've had restructuring, we've had new programs developing, we've had, you know, SARS. . . then H1N1. . all those kind of things throw you off a bit for a while" (\#7, broad population focus)., 5 For some, "access and equity, the diversity stuff, seems to be less important than maybe some other issues that are going on" (\#5, broad population focus).

Sustainability and the Learning Organization: ReFlection and Action

The discourse of continuous organizational learning was embedded in many of the narratives, with agency attention to ongoing critical reflection about processes and practices in order to identify priorities for action and to sustain successes. One KI used the phrase "learning organization" (\#2, racialized population focus), a familiar term in business and educational literature. This was particularly evident with the many references to intersectionalities 
of race/ethnicity and sexual and gender diversity in which organizations are working across differences of race/ethnicity, sexuality, age, ability, and gender, acknowledging and recognizing the complexity of differences and the energy it takes to do the work. As one KI said, "It's hard and right now we're doing [work with] the transgender community and I've never done any work with the bisexual community, which I've always wanted to do" (\#8, racialized population focus). Such ongoing attention to learning is crucial. As another KI noted, despite intensive training, over time, people move on, and funding-informed mandates shift. Agency public statements could still be there but are not supported by current priorities or staff:

You get a whole new group of people, so [policies, symbols of antioppression] could be up there still, right? But yet what we found out years later was that there were homophobic remarks being made to us [within our agency]... that training needs to continuously happen. (\#8, racialized population focus)

Working the System: Strategic Responses

Even enthusiastic advocates encountered reality checks as they worked day to day to improve LGBTQ access - in the process, illuminating strategic responses: "We have to plan for those moments when things plateau" (\#2, racialized population focus):

In the beginning [the goal] was to do this work so we could change the curriculum in Canada for health care providers. We soon learned that we were not going to be able to go down that road so that our route was to then develop these curriculum resources for those that they could incorporate any time. (\#8, racialized population focus)

Using funding proposals for LGBTQ-inclusive projects and programs was frequently noted as a key strategy to work sexual and gender diversity into agency functioning:

Many funders don't in fact fund GLBTQ as a funding stream but if you insert it they rarely say no. So, suddenly this funder that doesn't officially have a door for it can be a funder. ( $\# 2$, racialized population focus)

In this way agencies garnered support for LGBTQ issues at individual, organizational, community, and systems levels.

KIs named recruitment as a key issue for sustainability of LGBTQpositive space. One spoke of recent moves to explicitly recruit for LGBTQ-identified staff, but faced challenges going through central human resources rather than program-focused hiring processes. Several recently 
created transgender-specific programs with the recognition of the need to serve the diverse populations for whom gender identity and gender expression are key to their well-being and have encouraged employees to seek out supportive equity affiliations in workplaces or communities.

Evident throughout these narratives were the ways knowledge creation and exchange were often identified as priorities to inform the community engagement/assessment, organizational processes, education/training, and leadership initiatives. Participants used social media, clinical meetings, policy development, education, and research as opportunities to position themselves as LGBTQ advocates, create momentum, and foster relationship building across levels within and outside their agencies with LGBTQ and other communities and systems of care all in the larger goal of promoting the well-being of diversely situated LGBTQ people.

\section{DISCUSSION}

With their focus on confronting sources of inequity for the diverse groups which comprise LGBTQ populations, these KI narratives challenge the dominant discourse of "managing diversity" which acknowledges difference (e.g., cultural diversity discourse), with its focus on the individual, as it often impacts invisibility and lack of structural change. Instead, the themes resonate with the counter discourses of social determinants of health, anti-oppression, and citizen rights that require the reorientation of health services to promote a broad holistic view of well-being and sustainable social change Daley \& MacDonnell, 2011). Despite different organizational population foci, these KI agencies faced some similar challenges to implement positive space initiatives, especially in the context of competing agency priorities and mandates, ongoing challenges to keeping an anti-oppression focus, and limited resources. The findings are consistent with other health and social services literature that focuses on inclusive clinical spaces that point to interpersonal, structural, and systemic dynamics, including workplace policies as relevant to developing culturally competent clinical care for LGBT persons (Israel, Walther, Gortcheva, \& Perry, 2011; Wilkerson et al., 2011).

The ways that these organizations talked about LGBTQ involvement demonstrated a commitment to engagement and integration of LGBTQ knowledge, experiences, and practices, to enhance care and promote health. The focus on strengthening community action was evident when community engagement and leadership emerged as relevant, as did strategies to embed diverse LGBTQ voices and visibility in everyday functioning of organizations, although at times, challenges to representing diverse groups within LGBTQ people were raised as a concern. Participants spoke of community consultations, community soundings, and processes of building relationships with communities that reflected a goal of enhancing community capacity through 
community assessment and sustaining such partnerships and maintaining a LGBTQ voice in the agency well beyond that initial phase (e.g., City of Toronto, 2008; GLMA, 2001; Mottet \& Tanis, 2008).

The findings also point to comprehensive and concerted actions such as leadership, political advocacy, and strategic policy change at multiple levels, within and beyond their organizations that a number of participants identified as relevant to creating positive space and often echoed by health and social services access and equity literature from the United States and beyond (e.g., GLMA, 2001; IOM, 2011; Mulé et al., 2009). The National Institutes of Health and IOM (2011) are calling for LGBTQ research and a focus on health indicators that could potentially embed LGBTQ access in organizational functioning and in regulation of quality of care. The Health Equality Index (GLMA and the Human Rights Campaign Foundation, 2014), with its expanding list of organizations showing commitment to LGBTQ people, continues to encourage inclusive organizational change. Health equity impact assessment tools that have now been developed by Canada, Wales, and Australia offer organizations the potential to incorporate a health equity lens into programming for diverse LGBTQ people (The Wellesley Institute, 2009). As Gardner (2010) cautions, even when there are many competing priorities and ever-present cost-cutting pressures, the use of such an impact tool can be an important strategy to keep equity on organizational agendas. In Canada, in the absence of large-scale federal funding/research or a national organizational strategy that a number of other countries are implementing (e.g., Australian Government, 2012; Government Equalities Office, 2011; IOM, 2011; NHS Inclusion Project and Stonewall Scotland, 2005; Travers, in press), Rainbow Health Ontario (2013), funded by the Ontario Ministry of Health and Long-Term Care, has been involved in a range of education, research, and policy initiatives across Ontario (e.g., City of Toronto, 2008). Support for change in the home care sector would be facilitated by such broader political support and leadership.

Since this study data was collected in 2010, not only are those macrolevel strategies and LGBTQ research supports expanding, but in a Canadian context, positive space initiatives are surfacing in a variety of ways, including those that take into account the intersectional nature of LGBTQ populations agencies serve. For instance, the Ontario Council of Agencies Serving Immigrants (OCASI) has undertaken strategies to develop positive space in relation to care for immigrant and refugee newcomers (OCASI, 2014). A regional network affiliated with a youth mental health agency in Halton Region outside of Toronto, Ontario, the Positive Space Network (of Halton [PSN; 2014]), has developed standards to accredit local health and social service agencies, including "develop[ing] an internal action plan... [and] formal process, known to clients and community, by which experiences and challenges can be brought forward to PSN for resolution/mediation... identiflication] as an ally and a certified safe space for the LGBTQ+ population on the agency website, marketing materials and physical organizational space" (para. 6). 
Implications for Home Care

We began this study with a focus on enhancing access to home care and need to consider findings within this particular context-in terms of understanding challenges that the home care context may produce in relation to the findings just described. These findings are based on a particular set of communitybased health and social service agencies in an urban context with wellestablished LGBTQ communities and associated LGBTQ health and social service advocacy. Consideration must be given to the unique context of provision of home care compared to organization-based health and social services that will influence the potential implementation of strategies to foster positive space in that setting.

In Ontario, 14 Community Care Access Centres (CCACs) coordinate publicly funded home health care for people who meet eligibility criteria for acute or longer-term care. CCAC care coordinators or case managers determine client eligibility and provide case coordination. According to the Ontario Home Care Association (2014), approximately 650,000 clients across the age spectrum received home care services funded by CCAC in 2012-2013. Since it is estimated that LGBTQ people make up 5\% to $10 \%$ of the population (RNAO, 2007), it would be expected that thousands of LGBTQ clients will receive home care. Referrals and assessment for case management are managed by CCAC care coordinators who have health professional credentials (e.g., registered nurse, social worker). Based on assessment of need and available resources, they determine client eligibility and refer them to home services provided by contracted provider agencies. Care is predominately provided by nurses and personal support workers, with a smaller number of clients receiving care from social workers and occupational, physiotherapy, and speech language therapists who work for CCAC-contracted home care agencies.

\section{Nature of Service Provision}

Organizations that provide clinical care outside of institutional walls have particular challenges to ensure home care workers have the education, tools, and skills to engage in inclusive ways with diverse populations they serve (Irish, 2014). In institutional settings, agencies can potentially create their commitment to LGBTQ-inclusive programs and services (access, relevance, and visibility) through posters, rainbow stickers, and inclusive policies in client waiting rooms (Wilkerson et al., 2011). The absence of concrete institutional walls within the home care sector for this purpose suggests that more research is needed to examine how home care agencies, from CCAC to the contracted provider agencies, would engage in organizational processes that explicitly reflect LGBTQ inclusivity in their organizational mission 
and vision statements and show their diverse clients and families that their programs and services, which range from palliative care to mental health to short-term acute care support, are accessible for diverse LGBTQ clients. Given the invisibility of LGBTQ focus in home care, this study raises questions about how agencies will meet their diverse clients' needs by creating space for disclosure of sexual orientation and gender identity if desired, through, for example, intake and assessment forms and respectful interactions. It also suggests a need to examine how agencies and diverse individual providers can make affirmative space visible in the home setting in the absence of "institutional walls" which can easily display signifiers of positive space.

\section{Care in Privacy of Homes}

Receiving home care potentially has particular challenges for diverse groups of queer and trans people. Care in one's home brings with it a vulnerability to display of personal photos, mementos, and political markers such as rainbow flags. Illness may limit their ability to control the visibility of this aspect of their lives, yet they may fear exposure of their queer and/trans identities and unpredictable hostile negative provider responses and even poor quality of care; this vulnerability may be magnified for older patients/clients and those who are racialized or have a disability (Moore, 2009; Witten \& Eyler, 2012). The home care setting has implications for privacy in terms of workers not being seen. As one might say, "The walls have eyes in organizations." In the home setting, heterosexist, homophobic, biphobic, and transphobic actions, gestures, and expressions are less visible to others, including other providers, patients/clients, visitors, and organizational staff who are found in institutional environments.

Centrality of Family in the Provision of Care

In the Ontario home care context, with current CCAC intake forms having no provision for collecting client self-identification of sexual orientation and gender identity, heteronormative assumptions about family will shape client/provider interactions. Given the significant role that the family often plays in providing informal care, there are questions about how providers will determine a client's "significant supports or chosen family." Home care providers across the spectrum of the profession may not be aware of the often profound isolation that especially older LGBTQ seniors and LGBTQ people across the age spectrum living with the mental health impacts of 
homophobia and transphobia experience (Bauer et al., 2009; Finkenauer, Sherratt, Marlow, \& Brodey, 2012; Peterson, 2013; Witten \& Eyler, 2012).

\section{Diversity Within Priority Populations}

The findings raise questions about LGBT people being considered priority home care populations given the assumption that their health issues are limited to HIV/AIDS, mental health, and sexual health (Mulé et al., 2009). For older LGBTQ people, who may be assumed to represent the main home care users, literature documents the LGBT invisibility in seniors-related health and social service programs and services (Price, 2010; Witten \& Eyler, 2012), yet home care is provided to people across ages and conditions on a shortterm and long-term basis.

A recent article on trends in home care nursing which focuses on the American health care system (Irish, 2014) does not address LGBT people in relation to aging or other trends in nursing, although another article in Home Healthcare Nurse (Hines, 2014) focuses on cultural competence and mentions LGBT people briefly in relation to that. With few exceptions, LGBTQ people are invisible in the home care literature (Daley \& MacDonnell, 2014; Price, 2010). These study findings point to the importance of CCAC and their contracted provider organizations across Ontario in engaging LGBT communities and creating working partnerships to develop responsive and relevant education, training policies, and programs to meet the needs of their diverse clientele. However, given the historical invisibility of diverse LGBTQ people in home care literature, the study raises questions about whether home care agencies would recognize the importance and urgency of moving forward on this. Building home care sector capacity using organizational champions at multiple levels of organizations as a strategy to foster the development of positive space (Hendy \& Barlow, 2011) may be a way forward to foster awareness and action.

Complexity of service provision is well-recognized in home care contexts with some recommendations to increase home care nurses' educational preparation and skill sets to deal with the complexity of patients/clients in the often isolated context of the home setting (Irish, 2014). Patients/clients are often discharged home with need for multiple services, some short term and others long term, and would vary depending on resources available in particular service areas. Yet, many direct home care providers no longer work out of an office, so they may have limited access to immediate team supports for providing guidance to meet the needs of diverse clients, or have limited access to team meetings to discuss complex case management. There are questions about how home care organizations can ensure that all of their providers have adequate profession-specific training and education rather than all professions receiving "shallow" training - the equivalent of LGBTQ 101 (Daley \& MacDonnell, 2014). 
Multidisciplinary Service Providers/Mix of Regulated and Non-Regulated Providers

Home care sector providers in Ontario have a range of professional preparation (from a few months of training for personal support workers to undergraduate and graduate degrees for nurses, social workers, physiotherapists, and others). As well, practice standards and professional competencies vary with complex standards and related professional curriculum for regulated health professionals (e.g., nursing, social work) and limited education for personal support workers. There are challenges to implementing provider education and training that reflects the affirmative educational practices that are recommended in the literature (Biaggio et al., 2003; MacDonnell, 2009; Ussher, 2009). While many social work programs may use a social justice, anti-oppression lens and attend to intersectionality, not all disciplines including nursing or medicine are using this approach, instead focusing on transcultural approaches without attention to power and privilege. Exploratory research with home care providers in Ontario suggests that there is need for inclusive LGBT focus in professional curriculum as well as training (Daley \& MacDonnell, 2014). More research is needed, hence our large province-wide study to examine education and training as one aspect of understanding issues of access to home care from the perspective of service providers. Personal support workers who currently provide the mainstay of direct personal care in the home in Ontario receive limited education/training explicitly related to LGBT people or their health issues. While there are new Canadian home care nursing competencies, little is known about how and whether LGBT issues are addressed (Daley \& MacDonnell, 2014).

\section{Variety of Service Providers and Provider Agencies}

Ontario's home care sector is comprised of a mix of for-profit (private) and not-for-profit (public) contracted provider organizations. At any one time, a variety of agencies may be involved with home care provision of one patient/client. Currently, there are no mandates that address requirements for LGBTQ training/education for service providers affiliated with agencies that contract for services with CCAC. There are implications for differential access to training and education for service providers across agencies (with some clients getting workers from various agencies with various levels of access to training) and thus there are challenges to ensuring that clients receive consistently inclusive care from knowledgeable home care providers (Daley \& MacDonnell, 2014).

\section{Accountability}

The findings also raise questions about how the home care sector has policies and processes in place to show accountability to LGBTQ populations. Even if 
CCAC has a focus on patient-centered care, if LGBTQ issues are not explicitly considered in CCAC and their contracted service provider intake forms, as home care priority populations, in provider curriculum/training, in evaluation of programs and services, can home care agencies adequately meet client needs? Are there complaints processes in place that queer and trans people would feel safe using?

In summary, the unique features of the home care setting, including the nature of service provision outside of institutional walls and in the privacy of clients' homes, the complexity of care, diversity of service providers/types of agencies, and centrality of family, have implications for creating positive space that will provide responsive and relevant care for diverse LGBTQ people. The questions raised here can inform home care research about implementation of positive space in Ontario as well as in other countries, such as the United States, where home care provision shares many similarities to Canada (Irish, 2014) and gaps have been well-documented in relation to LGBTQ-focused professional education and the development of welcoming and responsive health care programs and services (IOM, 2011).

\section{Study Limitations}

This study has several significant limitations. Qualitative interview data were collected five years ago from a very small purposive sample of key informants in one large urban center in Ontario, Canada, which is considered to have well-developed queer and trans resources. The findings may not be relevant to other geographic locations. Data collected through qualitative interviews are co-constructed in the interview process and thus these narratives represent a snapshot of processes of organizational change as reported by these KIs in a dialogue with researchers in a particular time and place. For instance, other aspects of organizational change that were not shared in the interviews may have been relevant. Other KIs in these same organizations may have highlighted different aspects of organizational change than reported here. Although these participating KIs represented diverse sexual orientations and gender identities, demographic information about these identity categories was not collected. Such information would be useful to collect in future studies, along with information about self reports of ethnoracial, disability, and professional backgrounds to contextualize the findings. Interview questions did not include an explicit focus on measurable indicators or useful tools with examples from the access and equity literature that may have informed other directions for discussion of development of positive space.

\section{CONCLUSION}

The findings enhance an understanding of organizational processes, policy, and practices that may contribute to fostering service access for LGBTQ communities by embedding LGBTQ voice/visibility in the everyday functioning 
of the organizations as well as creating health-promoting partnerships and advocacy initiatives as part of system transformation aligned with enhancing health equity (Wise \& Nutbeam, 2007). The findings are relevant to LGBTQ communities, home care providers in administrative, education, and clinical care contexts, and those involved in population health promotion. Although this analysis is based on a Canadian context, these findings offer insight into organizational processes that foster inclusive and positive space in a range of health and social service organizations and thus have direct implications for the home care context. However, the unique context of home care raises many questions about how to implement processes to foster positive space. It is clear that given the gap in LGBTQ-related home care research, baseline data are needed to understand the current context of queer and trans people's experiences of home care, as well as an understanding of the provision of care from individuals and their affiliated home care organizations. Although home care research in relation to client assessment forms in the Ontario context is underway, to our knowledge, there are no other studies about LGBTQ home care access in Canada or elsewhere (Daley \& MacDonnell, 2014).

In Canada, where important progress has been made in health and social policies to support queer and trans people, a focus on health equity remains marginal in health. As one well-regarded Canadian academic in the area of public health and social policy stated recently, "In fact, the very concept of inequalities in health and health inequity has been largely ignored, it is the topic that dare not even speak its name" (Hancock, 2011, p. ii264). As this article has shown, however, there are many hopeful signs with increasing commitments to LGBTQ health on the radar. Health and social service providers and organizations have a key role to play in leading the way.

\section{ACKNOWLEDGMENTS}

We acknowledge contributions from research assistants Sivan Bomze, Natalie Lazier, and Liberty Karp on this project. We are grateful to the key informants who shared their stories.

Earlier versions of this article were presented to the Rainbow Health Ontario Conference, in Toronto, Ontario, in March 2010, and to the 4th National Conference for Community Health Nurses, Toronto, Ontario, in June 2010.

\section{FUNDING}

This research was supported by a Minor Research Grant and Junior Faculty Grant from Faculty of Liberal Arts and Professional Studies, York University. 
1. To review literature on the "positive space" concept, a search of health and social services literature using search terms such as positive space* OR affirmative policy* OR welcoming environment* OR affirmative practice* plus literature addressing cultural competence was undertaken. We also drew on a previous project's extensive systematic search of access and equity literature that yielded 24 health services access and equity documents addressing the provision of institutionally based health care (see Daley \& MacDonnell, 2011).

2. For instance, in this GLBT Health Access Project's (2010) "Community Standards of Practice for Provision of Quality Health Care Services for Gay, Lesbian, Bisexual and Transgendered Clients" associated indicators for the standard on confidentiality addressed client control over disclosure, staff training on confidentiality, and policies on written client consent for disclosure of information to third parties.

3. A fourth resource was "Pride in My Workplace" (n.d.) from the business sector offering insight into developing inclusive workplaces. According to the HEI (GLMA and the Human Rights Campaign Foundation, 2014), this benchmarking tool has been used to examine American health organizations annually since 2007 on LGBTQ-related organizational practices such as provider training.

4. Table 1 provides an example that illustrates five of the emergent categories with their associated codes documented in this initial phase of coding.

5. SARS: During 2002-2003, severe acute respiratory syndrome (SARS) was a priority focus for health globally.

6. H1N1: In 2009, a pandemic of influenza-type H1N1 had implications for health globally.

\section{REFERENCES}

Appleby, G. A., \& Anastas, J. W. (1998). Not just a passing phase: Social work with gay, lesbian, and bisexual people. New York, NY: Columbia University Press. Armstrong, P., Boscoe, M., Clow, B., Grant, K., Pederson, A., \& Willson, K. (2003). Reading Romanow: The implications of the final report of the Commission on the Future of Health Care in Canada for Women. Winnipeg, Manitoba, Canada: National Coordinating Group on Health Care Reform and Women, Canadian Women's Health Network.

Australian Government. (2012). National lesbian, gay, bisexual, transgender and intersex (LGBTI) ageing and aged care strategy. Canberra, Australia: Department of Health and Ageing Canberra, Commonwealth of Australia.

Australian Medical Association. (2002). Position statement on sexual identity and gender diversity. Retrieved from https://ama.com.au/media/ama-positionstatement-sexual-diversity-and-gender-identity

Bauer, G. R., Hammond, R., Travers, R., Kaay, M., Hohenadel, K. M., \& Boyce, M. (2009). "I don't think this is theoretical; this is our lives." How erasure impacts health care for transgender people. Journal of the Association of Nurses in AIDS Care, 20(5), 348-361.

Bauer, G. R., Travers, R. R., Hammond, R., \& Boyce, M. (2007). Trans PULSE: Report on Phase 1 \& Plans for Phases II and III. Trans PULSE Project, Toronto and London, Canada. Retrieved from http://transpulseproject.ca/research/report-onphase-i-plans-for-phases-ii-and-iii/

Biaggio, M., Orchard, S. Larson, J., Petrino, K., \& Mihara, R. (2003). Guidelines for gay/lesbian/bisexual-affirmative educational practices in graduate psychology programs. Professional Psychology: Research and Practice, 34(5), 548554. 
Bridges, S. K., Selvidge, M. M. D., \& Matthews, C. R. (2003). Lesbian women of color: Therapeutic challenges and issues. Journal of Multicultural Counseling and Development, 31, 113-130.

Brotman, S., Ryan, B., Jalbert, Y., \& Rowe, B. (2002). The impact of coming out on health and health care access: The experiences of gay, lesbian, bisexual, and two spirit people. Journal of Health and Social Policy, 15(1), 29.

Buddel, N. (2011). Queering the workplace. Journal of Gay \& Lesbian Social Services, 23(1), 131-146.

Canadian AIDS Society. Homophobia and AIDS Working Group. (1991). Homophobia, heterosexism and AIDS (2nd ed.). Ottawa, Canada: Canadian AIDS Society. City of Toronto. (2008). LGBT toolkit for creating culturally competent care for lesbian, gay, bisexual and transgender persons. Toronto, Canada: Author. Retrieved from www1.toronto.ca/city_of_toronto/longterm_care_ homes_services/files/pdf/lgbt_toolkit_2008.pdf

Crisp, C. (2005). Homophobia and use of gay affirmative practice in a sample of social workers and psychologists. Journal of Gay E Lesbian Social Services, 18(1), 51-70.

Crisp, C. (2007). Correlates of homophobia and use of gay affirmative practice among social workers. Journal of Human Behavior in the Social Environment, 14(4), 20.

Daley, A. E., \& MacDonnell, J. A. (2011). Gender, sexuality and the discursive representation of access and equity in health services literature: Implications for LGBT communities. International Journal for Equity in Health, 10, 40. doi:10.1186/1475-9276-10-40

Daley, A., \& MacDonnell, J. A. (2014). "That would have been beneficial": LGBTQ education for home care service providers. Health and Social Care in the Community, 1-10. Article first published online: 27 Nov 2014 | doi: 10.1111/hsc.12141

Dean, L., Meyer, I. H., Robinson, K., Sell, R. L., Sember, R., Silenzio, V. M. B.,... Tierney, R. (2000). Lesbian, gay, bisexual and transgender health: Findings and concerns. Journal of the Gay and Lesbian Medical Association, 4, 101-151.

Dobinson, C., MacDonnell, J., Hampson, E., Clipsham, J., \& Chow, K. (2005). Improving access and quality of public health services for bisexuals. Journal of Bisexuality, 5(1), 39-78.

Eliason, M. J., Dibble, S., \& DeJoseph, J. (2010). Nursing's silence on lesbian, gay, bisexual, and transgender issues: The need for emancipatory efforts. Advances in Nursing Science, 33(3), 206-218.

Finkenauer, S., Sherratt, J., Marlow, J., \& Brodey, A. (2012). When injustice gets old: A systematic review of trans aging. Journal of Gay and Lesbian Social Services, 24(4), 311-330.

Fish, J. (2009). Invisible no more? Including lesbian, gay and bisexual people in social work and social care. Practice: Social Work in Action, 21(1), 47-64.

Gapka, S., Raj, R., Chow, K., Clipsham, K., Hampson, E., \& MacDonnell, J. (2004). The trans health project. Position paper. Toronto, Canada: OPHA.

Gardner, B. (2010, August). Advancing equity in tough times [Policy briefing]. Toronto, Canada: Wellesley Institute. Retrieved from http://www.wellesley institute.com/wp-content/uploads/2010/09/LHINs_Briefing_-_Advancing_Equ ity_in_Tough_Times1.pdf 
Garrett, M. T., \& Barret, B. (2003). Two Spirit: Counselling Native American gay, lesbian, and bisexual people. Journal of Counselling and Development, 31, 131-142.

Gay and Lesbian Medical Association (GLMA). (2001). Healthy people 2010 companion document for LGBT health. Washington, DC: Author.

Gay and Lesbian Medical Association (GLMA). (2006). Guidelines for care of lesbian, gay, bisexual and transgender patients. San Francisco, CA: Author.

Gay and Lesbian Medical Association (GLMA) and the Human Rights Campaign Foundation. (2014). The Healthcare Equality Index: Promoting equitable and inclusive care for lesbian, gay, bisexual and transgender patients and their families (HEI). Washington, DC: Author. Retrieved from www.hrc.org/issues/ hei.asp

Gay, Lesbian, Bisexual and Transgender Health Access Project. (2010). Community standards of practice for provision of quality health care services for gay, lesbian, bisexual, and transgendered clients. Boston, MA: GLBT Health Access Project and JRI Health. Retrieved from http://www.glbthealth.org/CommunityStandardsofPractice.htm

Government Equalities Office. (2011, June). Working for lesbian, gay, bisexual and transgender equality: Moving forward. Policy report. Retrieved from https:// www.gov.uk/government/uploads/system/uploads/attachment_data/file/ 85482/lgbt-action-plan.pdf

Hancock, T. (2011). Health promotion in Canada: 25 years of unfulfilled promise. Health Promotion International, 26(S2), 263-267. doi:10.1093/heapro/dar061 Hankivsky, O., Reid, C., Cormier, R., Varcoe, C., Clark, N., Benoit, C., \& Brotman, S. (2010). Exploring the promises of intersectionality for advancing women's health research. International Journal for Equity in Health, 9, 5.

Hendy, J., \& Barlow, J. (2011). The role of the organizational champion in achieving health system change. Social Science \& Medicine, 74, 348-355.

Hines, D. (2014). Cultural competence: Assessment and education resources for home care and hospice clinicians. Home Healthcare Nurse, 32(5S), S4-S11.

Hsieh, H. F., \& Shannon, S. E. (2005). Three approaches to qualitative content analysis. Qualitative Health Research, 15(9), 1277-1288.

Hudspith, M. (2001). Caring for lesbian bealth: A resource for Canadian bealth care providers, policy makers and planners. Report 1-894356-16-0. British Columbia, Canada: Ministry of Health and Ministry Responsible for Seniors.

Institute of Medicine (IOM). (2011). The health of lesbian, gay, bisexual, and transgender people. Washington, DC: The National Academies Press.

Irish, K. (2014). Trends affecting the future of home healthcare. Home Healthcare Now, 32(9), 567-568.

Israel, T., Walther, W. A., Gortcheva, R., \& Perry, J. S. (2011). Policies and practices for LGBT clients: Perspectives of mental health services administrators. Journal of Gay \& Lesbian Mental Health, 15(2), 152-168.

Jackson, N., Johnson, M., \& Roberts, R. (2008). The potential impact of discrimination fears of older gays, lesbians, bisexual and transgender individuals living in smallto-moderate sized cities on long term health care. Journal of Homosexuality, 54(3), 325-329. 
Johnson, C. V., Mimiaga, M. J., \& Bradford, J. (2008). Health care issues among lesbian, gay, bisexual, transgender and intersex (LGBTI) populations in the United States: Introduction. Journal of Homosexuality, 54(3), 213-224.

Kaiser Permanente. (2000). A provider's handbook on culturally competent care: Lesbian, gay, bisexual and transgendered population. Oakland, CA: National Diversity Council, Kaiser Permanente.

Leonard, W. (Ed.). (2002). What's the difference? Health issues of major concern to gay, lesbian, bisexual, transgender and intersex (GLBTI) Victorians. Melbourne, Australia: Department of Human Services.

MacDonnell, J. A. (2009). Fostering nurses' political knowledges and practices: Education and political activation in relation to lesbian health. Advances in Nursing Science, 32(2), 158-172.

MacDonnell, J. A. \& Andrews, G. J. (2006). Placing sexuality in health policies: Feminist geographies and public health nursing. Geojournal, 65, 349-364. Makadon, H. J., Mayer, K., Potter, J., \& Goldhammer, H. (Eds.). (2007). Fenway guide to lesbian, gay, bisexual and transgender health. Philadelphia, PA: American College of Physicians.

Martinez, P., Barsky, A., \& Singleton, S. (2011). Exploring queer consciousness among social workers. Journal of Gay \& Lesbian Social Services, 23(2), 296-315. McGibbon, E. A., \& Etowa, J. B. (2009). Anti-racist health care practice. Toronto, Canada: Canadian Scholars' Press.

McNair, R. P., \& Hagarty, K. (2010). Guidelines for the primary care of lesbians, gay, and bisexual people: A systematic review. Annals of Family Medicine, 8(6), 533-541.

Moore, D. (2009). Designing long-term care for lesbian, gay, bisexual, transsexual and transgender people. In P. Armstrong, M. Boscoe, B. Claw, K. Grant, M. Haworth-Brockman, B. Jackson et al. (Eds.), A place to call home: Long-term care in Canada (pp. 104-110). Halifax, Canada: Fernwood Publishing.

Morris, T. (2006). Social work research methods: Four alternative paradigms. Thousand Oaks, CA: Sage.

Mottet, L., \& Tanis, J. (2008). Opening the door to the inclusion of transgender people: The nine keys to making lesbian, gay, bisexual and transgender organizations fully transgender-inclusive. New York, NY: National Gay and Lesbian Task Force Policy Institute and the National Center for Transgender Equality.

Mulé, N., Ross, L. E., Deeprose, B., Jackson, B. Daley, A., Travers, A., \& Moore, D. (2009). Promoting gender and sexually diverse health and wellbeing in policy development. Journal for Equity in Health, 8, 18.

Mullins, M. (2012). The relationship of practice beliefs and practice behaviors among social workers with lesbian and gay clients. Journal of Human Behavior in the Social Environment, 22, 1050-1064.

NHS Inclusion Project and Stonewall Scotland. (2005). Fair for all-The wider challenge. Good LGBT practice in the NHS. Glasgow, Scotland: NHS Scotland and Stonewall Scotland.

O'Connor, M., Denton, M., Hajdukowski-Ahmed, M., Zeytinoglu, I. U., \& Williams, K. (1999). A theoretical framework for research on women's health promotion. In M. Denton, M. Hadjukowski-Ahmed, M. O'Connor, \& I. U. Zeytinoglu (Eds.), Women's voices in bealth promotion (pp. 9-20). Toronto, Canada: Canadian Scholars' Press. 
Ontario Council of Agencies Serving Immigrants. (OCASI). (2014). About positive spaces: What and why. Retrieved from http://www.positivespaces.ca/whypositive-spaces

Ontario Home Care Association. (2014). Facts and figures: Publically funded bome care. Retrieved from http://www.homecareontario.ca/public/about/homecare/system/facts-and-figures.cfm

Ontario Public Health Association (OPHA). (2011). A positive space is a healthy place: Making your community health centre or public health unit inclusive to those of all sexual orientations and gender identities. Toronto, Canada: Author.

Peterson, C. (2013). The lies that bind: Heteronormative constructions of "family" in social work discourse. Journal of Gay \& Lesbian Social Services, 25(4), 486-508. Positive Space Network of Halton. (2014). Positive space network LGBTQ+ certification project. Retrieved from http://www.positivespacenetwork.org/

Price, E. (2010). Coming out to care: Gay and lesbian carers' experiences of dementia services. Health and Social Care in the Community, 18(2), 160-168.

The Public Advocate for the City of New York. (2008). Improving lesbian, gay, bisexual and transgender access to healthcare at New York City Health and Hospitals Corporation facilities. New York, NY: Office of the Public Advocate for the City of New York.

Rainbow Health Ontario (RHO). (2013). RHO mission and vision. Retrieved from http://www.rainbowhealthontario.ca/about-us/

Rankin, S. R. (2007). Campus climate for sexual minorities. In M. V. L. Badgett \& J. Frank (Eds.), Sexual orientation discrimination: An international perspective (pp. 236-252). London, England: Routledge.

Registered Nurses Association of Ontario (RNAO). (2007). Respecting sexual orientation and gender identity. Position statement. Toronto, Canada: Author. Retrieved from http://rnao.ca/policy/position-statements/sexual-orientationgender-identity

Röndahl, G., Innala, S., \& Carlsson, M. (2007). To hide or not to hide, that is the question! Lesbians and gay men describe experiences from nursing work environment. Journal of Homosexuality, 52(3/4), 211-233.

Ryan, B., Brotman, S., Baradaran, A., \& Lee, E. (2008). The colour of queer health care: Experiences of multiple oppression in the lives of queer people of colour in Canada. In S. Brotman \& J. J. Lévy (Eds.), Intersections: cultures, sexualités et genres (pp. 307-317). Québec City, Canada: Presses de l'Université du Québec. Singh, A. A., Meng, S., \& Hansen, A. (2013). "It's already hard enough being a student": Developing affirming college environments for trans youth. Journal of LGBT Youth, 10(3), 208-223.

Spillane, J. (2006). Distributed leadership. San Francisco, CA: Jossey Bass.

Travers, A. (in press). The health of sexual minority women and trans people: An Ontario perspective. In P. Armstrong \& J. Deadman (Eds.), Women's health: Intersections of policy, research and practice. Toronto, Canada: Women's Press. University of Toronto. (2014). Welcome to the University of Toronto's positive space campaign website. Retrieved from http://www.positivespace.utoronto.ca

Ussher, J. (2009). Heterocentric practices in health research and health care: Implications for mental health and subjectivity of LGBTQ individuals. Feminism $\&$ Psychology, 19(4), 561. 
Valentine, G., Wood, N., \& Plummer, P. (2009, March). The experience of lesbian, gay, bisexual and trans staff and students in higher education: Research report. London, England: Equality Challenge Unit.

The Wellesley Institute. (2009). Templates and user guides for equity-focused impact assessment. Retrieved from http://www.wellesleyinstitute.com/health/ user_guides_to_equity-focused_impact_assessment/

Whealin, J. M., \& Ruzek, J. (2008). Program evaluation for organizational cultural competence in mental health practices. Professional Psychology: Research and Practice, 39(3), 320-328.

Wilkerson, M. J., Rybicki, S., Barber, C. A., \& Smolenski, D. J. (2011). Creating a culturally competent clinical environment for GLBTQ patients. Journal of Gay E Lesbian Social Services, 23(3), 376-394.

Wise, M., \& Nutbeam, D. (2007). Enabling health systems transformation: What progress has been made in re-orienting health services? Global Health Promotion, 14(2), Supplement, 23-27.

Witten, T. M., \& Eyler, A. E. (2012). Gay, lesbian, bisexual and transgender aging: Challenges in research, practice \& policy. Baltimore, MD: Johns Hopkins Press.

\section{APPENDIX: INTERVIEW QUESTIONS}

1. Describe how issues of access and equity are addressed in your organization.

2. Your organization is known for its programming related to sexual diversity/gender variance. What makes this a queer- and/or trans-positive organization?

3. From your perspective what factors led to this programming/organizational focus? (enablers)

4. Were there key turning points?

5. Were key people, departments, or roles involved?

6. Were there internal policies or political dynamics that contributed?

7. Were there external policies or political dynamics at play?

8. What challenges were encountered? How were these addressed?

9. What policies focus on (1) patient/client, (2) employee, (3) employer issues?

10. What supports are there to implement/operationalize these policies?

11. How have issues of race/ethnicity, ability, gender, etc., been relevant to the process?

12. Are there particular areas that the organization has identified as continued areas for development? How are the priorities or gaps identified? 